\title{
Mechanisms of resistance to vitamin D action in human cancer cells
}

\section{María Jesús Larriba and Alberto Muñoz}

Instituto de Investigaciones Biomédicas "Alberto Sols", Consejo Superior de Investigaciones Científicas-Universidad Autónoma de Madrid, Arturo Duperier 4, E-28029 Madrid, Spain. Corresponding autor: Alberto Muñoz. E-mail: amunoz@iib.uam.es

\begin{abstract}
Initial clinical trials in cancer patients with vitamin D compounds have shown acceptable toxicity but low activity. A number of mechanisms responsible for resistance to their action in cancer cells have been recently reported. They include reduced intracellular availability of 1 $\alpha, 25$-dihydroxyvitamin $\mathrm{D}_{3}\left(1,25(\mathrm{OH})_{2} \mathrm{D}_{3}\right)$, loss of vitamin $\mathrm{D}$ receptor (VDR) expression and deregulation of transcription corepressors that modulate VDR action. Here, we summarize the data in the literature on the altered activity of the enzymes (CYP27B1, CYP24A1) that controls $1,25(\mathrm{OH})_{2} \mathrm{D}_{3}$ levels, the repression of VDR by the transcription factor Snaill and the overexpression of several VDR corepressors (NCoR, SMRT) in cancer cells. A better understanding of these processes must contribute to improved protocols for the clinical use of vitamin D compounds.
\end{abstract}

Keywords Vitamin D resistance, CYP27B1, CYP24A1, VDR repression, VDR corepressors Acknowledgements

We apologize to colleagues whose work were either inadvertently overlooked or not cited due to space limitations. We thank Robin Rycroft for his help with the English manuscript. The work in authors' laboratory is supported by the Ministerio de Ciencia e Innovación of Spain, Comunidad de Madrid and European Union. 
The classical consideration of vitamin $\mathrm{D}$ as a regulator of calcium and phosphate metabolism and bone biology began to change in 1981, when David Feldman's and Tatsuo Suda's groups showed that the most active vitamin $\mathrm{D}$ metabolite $1 \alpha, 25$-dihydroxyvitamin $\mathrm{D}_{3}\left(1,25(\mathrm{OH})_{2} \mathrm{D}_{3}\right.$, calcitriol) inhibited the proliferation of melanoma cells and induced the differentiation of leukemic cells $[1,2]$. These seminal, pioneer findings opened a new era in the study of $1,25(\mathrm{OH})_{2} \mathrm{D}_{3}$, which is now seen as a hormone with pleiotropic effects in the organism. A large number of epidemiological and experimental studies performed in cultured cells and animal models over the last thee decades support a cancer preventive and, perhaps, a therapeutic role for $1,25(\mathrm{OH})_{2} \mathrm{D}_{3}$ and a series of synthetic vitamin $\mathrm{D}$ analogs [3, 4, reviews]. The initial phase I and phase II cancer clinical studies showed acceptable toxicity but low activity of these compounds [5, review]. As is usual in the development of new antitumoral drugs, patients enrolled in these trials were not responding to any other therapy, and they were unselected in terms of putative responsiveness to vitamin D compounds. Recent data on the physiology of the vitamin D system improve our understanding of the action of $1,25(\mathrm{OH})_{2} \mathrm{D}_{3}$ at the molecular and cellular level, which may in turn help us to design future clinical trials more rationally. In this chapter, we summarize current knowledge on the mechanisms that dictate the response or resistance to $1,25(\mathrm{OH})_{2} \mathrm{D}_{3}$ in human cancer cells. The mechanisms have been grouped into three classes: a) the bioavailability of $1,25(\mathrm{OH})_{2} \mathrm{D}_{3}$ in the cell, b) the integrity and level of expression of the vitamin D receptor (VDR); and c) the pattern of expression of the transcription coregulators (coactivators and corepressors) that modulate VDR action.

$1,25(\mathrm{OH})_{2} \mathrm{D}_{3}$ action in human cancer cells. The anticancer action of $1,25(\mathrm{OH})_{2} \mathrm{D}_{3}$ relies on several mechanisms at the cell level: inhibition of proliferation, invasion and angiogenesis, sensitization to apoptotic stimuli, induction of differentiation, and modulation of the immune 
system [3-5]. In each type of cancer, the combined effect of these mechanisms on tumor and stromal cells may determine $1,25(\mathrm{OH})_{2} \mathrm{D}_{3}$ action.

$1,25(\mathrm{OH})_{2} \mathrm{D}_{3}$ has two types of effect on target cells: the regulation of transcription rate of a large number of genes (genomic effects), and the rapid, transcription-independent modulation of the activity of membrane ion channels and cytosolic kinases, phosphatases and phospholipases (non-genomic effects). Most studies indicate that both types of effect are mediated by $1,25(\mathrm{OH})_{2} \mathrm{D}_{3}$ binding to, and activation of VDR. This is a member of the superfamily of nuclear receptors that is expressed in many cell types, and it acts as a ligandmodulated transcription factor regulating gene expression. A few studies have proposed the existence of $1,25(\mathrm{OH})_{2} \mathrm{D}_{3}$ receptors other than VDR, but their confirmation as physiological mediators of $1,25(\mathrm{OH})_{2} \mathrm{D}_{3}$ action is pending $[3,5]$.

The current model for gene activation by $1,25(\mathrm{OH})_{2} \mathrm{D}_{3}$-VDR predicts that unliganded VDR bound (forming a heterodimer with RXR, the retinoid X receptor) to regulatory sequences (vitamin D response elements or VDRE) in target genes represses their transcription by recruiting corepressors (NCoR, SMRT ...) and histone deacetylases. $1,25(\mathrm{OH})_{2} \mathrm{D}_{3}$ induces a conformational change in VDR that results in the replacement of corepressors by coactivators $(\mathrm{SRC} 1, \mathrm{NCoA} 2 \ldots)$ and increased histone acetylase activity. This results in the opening of chromatin structure thus allowing entry of the basal RNA polymerase II transcription machinery (Fig. 1) [6, review]. The mechanism of gene repression by $1,25(\mathrm{OH})_{2} \mathrm{D}_{3}$ is less known, although this process is probably equally important for its action, as around one third of the target genes are inhibited. In addition to the direct blockade of RNA polymerase II activity by binding to VDREs located close to the transcription initiation site, gene repression may be due to competition for DNA binding with other transcription factors or to interference of their transcription regulatory function (by protein-protein interaction or modulation of their phosphorylation) [5]. 
These considerations indicate that $1,25(\mathrm{OH})_{2} \mathrm{D}_{3}$ acts by modulating VDR action, and that such action is fine-tuned by its interaction with coregulators (coactivators and corepressors). $1,25(\mathrm{OH})_{2} \mathrm{D}_{3}$ is the most active vitamin $\mathrm{D}$ metabolite because it has the highest affinity for VDR binding. 1,25(OH) $)_{2} \mathrm{D}_{3}$ is synthesized from 25-hydroxyvitamin $\mathrm{D}_{3}\left(25(\mathrm{OH}) \mathrm{D}_{3}\right)$ by the action of the 25-hydroxyvitamin $\mathrm{D}_{3} 1 \alpha$-hydroxylase (CYP27B1). As discussed below, this has long been thought to take place only in the kidney, but it is now known to occur in several other cell types including colon, breast, and prostate normal and transformed epithelial cells. Intracellularly, $1,25(\mathrm{OH})_{2} \mathrm{D}_{3}$ is degraded by further hydroxylation at position 24 by the ubiquitous enzyme 24-hydroxylase (CYP24A1) [3, 5].

In summary (Fig. 1), cell responsiveness to $1,25(\mathrm{OH})_{2} \mathrm{D}_{3}$ primarily relies on the expression of VDR. Second, VDR activity depends on cellular $1,25(\mathrm{OH})_{2} \mathrm{D}_{3}$ levels that result from the balance between the circulating concentrations of $25(\mathrm{OH}) \mathrm{D}_{3}$ and $1,25(\mathrm{OH})_{2} \mathrm{D}_{3}$, that cross the plasma membrane by either passive or facilitated (carrier-mediated) diffusion, and the cellular activity of CYP27B1 and CYP24A1 enzymes that control $25(\mathrm{OH}) \mathrm{D}_{3}$ conversion into $1,25(\mathrm{OH})_{2} \mathrm{D}_{3}$ and subsequent degradation of this molecule. Third, the pattern of expression of coactivators and corepressors modulates VDR activity, thus establishing the precise mode and strength of the effects of $1,25(\mathrm{OH})_{2} \mathrm{D}_{3}$ on the transcription of target genes. An additional overimposed level of regulation comes from other signals that may trigger molecular pathways affecting the post-translational (phosphorylation) modification, intracellular location, or half-life (polyubiquitylation) of VDR or any of its coregulators.

Resistance due to reduced bioavailability of $1,25(\mathrm{OH})_{2} \mathrm{D}_{3}$ within cancer cells. Ligand occupancy and activation of VDR depends on the levels of circulating $25(\mathrm{OH}) \mathrm{D}_{3}$ (nM range) and $1,25(\mathrm{OH})_{2} \mathrm{D}_{3}$ (pM range) that enter the cell from the bloodstream and on the cellular activity of CYP27B1 and CYP24A1 enzymes that regulate respectively the conversion of $25(\mathrm{OH}) \mathrm{D}_{3}$ into $1,25(\mathrm{OH})_{2} \mathrm{D}_{3}$ and the degradation of this molecule. Obviously, vitamin $\mathrm{D}$ 
deficiency due to insufficient vitamin $\mathrm{D}_{3}$ synthesis or diet contribution will determine low circulating $25(\mathrm{OH})_{2} \mathrm{D}_{3}$ levels. Decreased renal CYP27B1 expression or activity has the same consequence. Kidney CYP27B1 was long time considered the only source of $1,25(\mathrm{OH})_{2} \mathrm{D}_{3}$, which would then reach the bloodstream and act on target tissues in an endocrine fashion. The finding, however, of CYP27B1 expression and activity in normal and tumoral colon epithelial cells and later in other cell types (prostate, breast) demonstrated that $1,25(\mathrm{OH})_{2} \mathrm{D}_{3}$ has paracrine and autocrine activity that may be involved in a defense mechanism against cancer progression $[7,8] .1,25(\mathrm{OH})_{2} \mathrm{D}_{3}$ rapidly and strongly induces CYP24A1 expression, leading to an increase in the metabolism of $1,25(\mathrm{OH})_{2} \mathrm{D}_{3}[8]$. Interestingly, a number of studies have reported differences in CYP27B1 and/or CYP24A1 expression/activity between normal and tumoral cells. This has led to the currently accepted idea that, in cancer cells, attenuated CYP27B1 expression or activity or accelerated $1,25(\mathrm{OH})_{2} \mathrm{D}_{3}$ elimination by CYP24A1 overexpression leads to reduced VDR activation and $1,25(\mathrm{OH})_{2} \mathrm{D}_{3}$ resistance. Colon, prostate and breast cancer cells in culture show reduced CYP27B1 expression, which in some cases appears to be a consequence of epigenetic alteration of the genetic locus, as treatment of cells with methylation or deacetylation inhibitors increased CYP27B1 expression [9]. One study has proposed that the mechanism of decreased CYP27B1 activity in prostate cancer cell lines is via decreased gene expression while in primary cultures and tissues it is post-translational [10]. Moreover, the finding that CYP27B1 is also present in tumor infiltrating macrophages suggests an immunomodulatory component of $1,25(\mathrm{OH})_{2} \mathrm{D}_{3}$ production in some types of cancer [8].

CYP24A1 overexpression is commonly held responsible for the partial or total resistance of colon, breast and prostate cancer cells to $1,25(\mathrm{OH})_{2} \mathrm{D}_{3}$ effects. In line with this, combination of $1,25(\mathrm{OH})_{2} \mathrm{D}_{3}$ with inhibitors of vitamin $\mathrm{D}_{3}$ metabolizing enzymes or antisense inhibition of CYP24A1 caused a greater inhibition of proliferation of human prostate and breast cancer 
cells than $1,25(\mathrm{OH})_{2} \mathrm{D}_{3}$ alone $[11,12]$. In colon cancer cells, $1,25(\mathrm{OH})_{2} \mathrm{D}_{3}$ downregulates CYP27B1 and induces CYP24A1 in such a way that CYP27B1 is active only if CYP24A1 is not maximally functional, and that the malignancy of tumor cells determines the extent of $1,25(\mathrm{OH})_{2} \mathrm{D}_{3}$ catabolism [13]. Additionally, CYP24A1 polymorphisms or splicing variants (modulated by $1,25(\mathrm{OH})_{2} \mathrm{D}_{3}$ ) may render different levels of constitutive and inducible CYP24A1 activity at least in prostate cancer cell lines [14]. The relevance of CYP24A1 regulation has recently been extended by the finding that epigenetic silencing of CYP24A1 contributes to the selective growth inhibition that $1,25(\mathrm{OH})_{2} \mathrm{D}_{3}$ induces in tumor-derived endothelial cells as compared to endothelial cells of non-tumor origin [15].

Taken together, these data indicate that enzymes involved in vitamin D metabolism may be important targets for cancer prevention and treatment. This is supported by in vitro studies that use epigenetic inhibitors or vitamin D analogs that prevent the increase of CYP24A1 activity [16]. Furthermore, antineoplastic agents of clinical use such as daunorubicin hydrochloride, etoposide and vincristine sulphate increase the intracellular level of $1,25(\mathrm{OH})_{2} \mathrm{D}_{3}$ by decreasing the stability of $C Y P 24 A 1$ mRNA [17]. This action would prolong the bioavailability of $1,25(\mathrm{OH})_{2} \mathrm{D}_{3}$ and may thus form the basis for putative additive or synergistic anticancer treatments. Importantly, during the aging the activity of CYP27B1 decreases while that of CYP24A1 increases, which contributes to partial resistance to vitamin $\mathrm{D}$ in the elderly.

Resistance to $1,25(\mathrm{OH})_{2} \mathrm{D}_{3}$ due to VDR repression. Cellular response to $1,25(\mathrm{OH})_{2} \mathrm{D}_{3}$ mainly depends on VDR expression levels. VDR is expressed in almost all cell types and tissues. Epithelial cells from gastrointestinal tract, breast, kidney, prostate, bladder and liver contain VDR. Moreover, VDR is expressed in bone, muscle and skin cells as well as some activated cells of the immune system [3]. Tumor cells derived from these tissues usually express VDR and maintain the capacity to respond to $1,25(\mathrm{OH})_{2} \mathrm{D}_{3}$. Remarkably, elevated VDR expression 
is associated with high differentiation, absence of node involvement and favourable prognosis in colorectal cancer [18-20], and with late development of lymph node metastases and longer disease-free survival in breast cancer [21, 22]. However, downregulation of VDR expression has been found in several tumors (colon, breast, lung...) compared with their corresponding normal tissue [7, 23]. In colon cancer, VDR expression is induced in the early stages of tumorigenesis (polyps and adenomas) and decreases during colon cancer progression [7]. Clinical response to $1,25(\mathrm{OH})_{2} \mathrm{D}_{3}$ analogs requires the expression of VDR in tumoral cells. Therefore, the downregulation of VDR found in tumors will lead to $1,25(\mathrm{OH})_{2} \mathrm{D}_{3}$ unresponsiveness and resistance not only to the therapy with $1,25(\mathrm{OH})_{2} \mathrm{D}_{3}$ analogs but also to the antitumoral effects of endogenous $1,25(\mathrm{OH})_{2} \mathrm{D}_{3}$.

Deletions, rearrangements or point mutations affecting the coding region of the $V D R$ gene have not been found in cancer. Several polymorphisms have been described in the $V D R$ gene, some of which have been associated with increased risk of breast, prostate and colon cancer. However, their consequences for VDR expression or functionality, and therefore their implication in the development of $1,25(\mathrm{OH})_{2} \mathrm{D}_{3}$ resistance remain to be established [24]. A mechanism responsible for VDR downregulation, at least in colon cancer, has emerged in the last years. Our group has revealed that the transcription factor Snaill binds to the human $V D R$ gene promoter and represses its expression in human colon cancer cells. In addition, Snail1 also reduces VDR mRNA half-life [25]. Accordingly, overexpression of Snail1 in human colon cancer cells blocks the prodifferentiation action of $1,25(\mathrm{OH})_{2} \mathrm{D}_{3}$ and its inhibitory effect on cell proliferation and migration. Snail1 also represses VDR expression and abrogates the antitumoral effect of $\mathrm{EB} 1089\left(\mathrm{a} 1,25(\mathrm{OH})_{2} \mathrm{D}_{3}\right.$ analog) in xenografted mice (Fig. 2) [25, 26]. Upregulation of Snail1 has been found in approximately $60 \%$ of colon tumors and it has been significantly associated with diminished VDR expression [25, 27]. These data indicate that Snail1 induction is probably responsible for VDR downregulation 
during colon cancer progression and indicate that tumors with high Snaill expression would be resistant to treatment with $1,25(\mathrm{OH})_{2} \mathrm{D}_{3}$ or its analogs. Since Snail1 is up-regulated in advanced tumors (associated with acquisition of migratory and invasive properties), $1,25(\mathrm{OH})_{2} \mathrm{D}_{3}$ and its analogs should preferentially be used as chemopreventive drugs, particularly for high risk patients, and as chemotherapeutic agents to be administered during the early stages of carcinogenesis [28]. In addition, as Snail1 up-regulation has been reported in cancers other than colon (synovial sarcoma and breast, gastric and hepatocellular carcinomas) [29, review] this mechanism could be responsible for VDR downregulation and vitamin D resistance in other tumors. It has also been shown that $H$-ras transformation of HC11 mammary cells or NIH 3T3 fibroblasts provokes a reduction of VDR mRNA levels leading to $1,25(\mathrm{OH})_{2} \mathrm{D}_{3}$ resistance. In these cases, transcriptional repression was ruled out and VDR downregulation seemed to be due to a decrease in VDR mRNA stability [30, 31]. As the Ras-Raf-MAPK pathway is one of the inducers of Snail1 [29], VDR downregulation by oncogenic $H$-ras is probably mediated by Snail1. Remarkably, ectopic VDR re-expression diminished $H$-ras-induced transformation in NIH 3 T3 cells [31].

Several studies have identified compounds that increase VDR expression and/or $1,25(\mathrm{OH})_{2} \mathrm{D}_{3}$ level in cancer and, therefore, could overcome the $1,25(\mathrm{OH})_{2} \mathrm{D}_{3}$ resistance of tumors. $1,25(\mathrm{OH})_{2} \mathrm{D}_{3}$ synthesis and VDR expression can be regulated by estrogens in colon cancer. $17 \beta$-estradiol and certain phytoestrogens induce VDR and CYP27B1 expression while they reduce that of CYP24A1. Therefore, the treatment of tumors with estrogens would increase VDR levels and overcome the resistance to $1,25(\mathrm{OH})_{2} \mathrm{D}_{3}$ analogs [32]. In addition, the transcription factor $\mathrm{p} 53$ and its family members $\mathrm{p} 63 \gamma, \mathrm{p} 73 \alpha$ and $\mathrm{p} 73 \beta$ activate human $V D R$ gene transcription. These transcription factors are activated in turn by genotoxic stresses such as certain chemotherapeutic drugs. It is therefore expected that combined treatment with 
chemotherapy may enhance cell sensitivity to the antitumoral effects of $1,25(\mathrm{OH})_{2} \mathrm{D}_{3}$ because the increase in the levels of p53 family members by chemotherapy could induce VDR [32]. Resistance to $1,25(\mathrm{OH})_{2} \mathrm{D}_{3}$ due to altered expression of VDR coregulators. Interestingly, tumoral resistance to $1,25(\mathrm{OH})_{2} \mathrm{D}_{3}$ appears to be unrelated to VDR levels in several situations, because there is no clear relation between VDR expression and $1,25(\mathrm{OH})_{2} \mathrm{D}_{3}$ action [24]. Therefore, various groups began to examine whether epigenetic mechanisms were disrupting VDR signalling, and they found that these mechanisms caused decreased responsiveness to $1,25(\mathrm{OH})_{2} \mathrm{D}_{3}$ in prostate and breast cancer [33]. This epigenetic corruption results from an abnormal pattern of expression of corepressors or coactivators. In addition, altered post-translational modifications of VDR or RXR may also diminish VDR transcriptional activity.

Elevated expression of the corepressors SMRT and NCoR has been reported in prostate and breast cancer cell lines, respectively [34, 35]. Moreover, an increased ratio of corepressor/VDR RNA is also observed in matched primary tumor and normal breast cells, particularly associated with estrogen receptor negativity [35]. This alteration causes resistance to the antiproliferative effect of $1,25(\mathrm{OH})_{2} \mathrm{D}_{3}$, which can be restored with inhibitors of histone deacetylases (trichostatin) and DNA methyltransferases (5-aza-2'-deoxycytidine) [34-36]. This also explains the synergistic inhibitory effect of combined treatment with $1,25(\mathrm{OH})_{2} \mathrm{D}_{3}$ and sodium butyrate or trichostatin on the proliferation of prostate cancer cells [37]. The abnormal expression of coregulators may explain why VDR content does not predict the antiproliferative effects of $1,25(\mathrm{OH})_{2} \mathrm{D}_{3}$ in some cancer cells [24]. Interestingly, in line with the increasing tendency to consider stroma as a critical regulator of tumor progression, altered VDR-mediated transcriptional activity due to abnormal VDR DNA binding and SMRT recruitment has been described in prostate cancer stroma [38]. 
In contrast to what happens with corepressors, there is no report of alterations in the expression of VDR coactivators. The lack of such alterations in cancer cells may be a consequence of a dominant role of corepressor overexpression, which upsets the equilibrium between the two types of coregulators in normal cells. Bikle and collaborators hypothesized that the reason why squamous cell carcinoma cells fail to respond to the prodifferentiating action of $1,25(\mathrm{OH})_{2} \mathrm{D}_{3}$, in spite of having normal levels of VDR and normal binding of VDR to VDREs, is a failure of the sequential binding of coactivator complexes to VDR [39]. Finally, although data in the literature are scarce, deregulation of the translational modifications of VDR and RXR are believed to affect the gene regulatory activity of $1,25(\mathrm{OH})_{2} \mathrm{D}_{3}$. In the transformed human keratinocyte cell line HPK1Aras, RXR $\alpha$ is phosphorylated at serine 260, which attenuates the transcriptional activity of VDR-RXR heterodimers and results in resistance to the growth inhibitory action of $1,25(\mathrm{OH})_{2} \mathrm{D}_{3}[40]$. HPK1Aras cells overexpress the H-ras oncogene and consequently exhibit an activated RasRaf-MAPK pathway. As this pathway is usually activated in many human cancer cells due to mutation or overexpression of membrane tyrosine kinase receptors (EGFR, MET) or downstream components such Ras or Raf, the importance of this type of alteration may be greater than suspected. VDR is known to be phosphorylated at several residues, although the significance of this remains to be assessed.

Concluding remarks. $1,25(\mathrm{OH})_{2} \mathrm{D}_{3}$ is a pleiotropic hormone with a complex variety of actions in the organism which are mediated by its high affinity receptor VDR, present in most cell types. VDR is expressed by many tumor cells. However, partial-to-total resistance to the antitumoral effects of $1,25(\mathrm{OH})_{2} \mathrm{D}_{3}$ arises during tumor progression. This is due to the reduced levels of $1,25(\mathrm{OH})_{2} \mathrm{D}_{3}$ in cancer cells, loss of VDR expression or deregulation of VDR transcriptional activity. The molecular mechanisms responsible for these alterations are, respectively, the deregulation of the enzymes synthesizing and degrading $1,25(\mathrm{OH})_{2} \mathrm{D}_{3}$ 
intracellularly (CYP27B1 and CYP24A1), the upregulation of Snail1 and perhaps other transcriptional repressors of VDR, and alterations in the synthesis or post-translational modifications of VDR corepressors or partners. Better understanding of these mechanisms of resistance may allow us to improve the anticancer therapy with $1,25(\mathrm{OH})_{2} \mathrm{D}_{3}$ and its analogs.

\section{References}

1. Abe E, Miyaura C, Sakagami H et al (1981) Differentiation of mouse myeloid leukemia cells induced by 1alpha,25-dihydroxyvitamin $D_{3}$. Proc Natl Acad Sci USA 78:4990-4994 2. Colston K, Colston MJ, Feldman D (1981) 1,25-dihydroxyvitamin $\mathrm{D}_{3}$ and malignant melanoma: the presence of receptors and inhibition of cell growth in culture. Endocrinology 108:1083-1086

3. Hansen CM, Binderup L, Hamberg KJ et al (2001) Vitamin D and cancer: effects of $1,25(\mathrm{OH})_{2} \mathrm{D}_{3}$ and its analogs on growth control and tumorigenesis. Front Biosci 6:D820-D848

4. Ordóñez-Morán P, Larriba MJ, Pendás-Franco N et al (2005) Vitamin D and cancer: an update of in vitro and in vivo data. Front Biosci 10:2723-2749

5. Deeb KK, Trump DL, Johnson CS (2007) Vitamin D signalling pathways in cancer: potential for anticancer therapeutics. Nat Rev Cancer 7:684-700

6. Sutton ALM, MacDonald PN (2003) Vitamin D: more than a "bone-a-fide" hormone. Mol Endocrinol 17:777-791

7. Cross HS, Kállay E, Khorchide M et al (2003) Regulation of extrarenal synthesis of 1,25dihydroxyvitamin $\mathrm{D}_{3}$-relevance for colonic cancer prevention and therapy. Mol Aspects Med $24: 459-465$

8. Townsend K, Evans KN, Campbell MJ et al (2005) Biological actions of extra-renal 25hydroxyvitamin D-1alpha-hydroxylase and implications for chemoprevention and treatment. 
J Steroid Biochem Mol Biol 97:103-109

9. Khorchide M, Lechner D, Cross HS (2005) Epigenetic regulation of vitamin D hydroxylase expression and activity in normal and malignant human prostate cells. J Steroid Biochem Mol Biol 93:167-172

10. Ma JF, Nonn L, Campbell MJ et al (2004) Mechanisms of decreased Vitamin D 1alphahydroxylase activity in prostate cancer cells. Mol Cell Endocrinol 221:67-74

11. Townsend K, Banwell CM, Guy M et al (2005) Autocrine metabolism of vitamin D in normal and malignant breast tissue. Clin Cancer Res 11:3579-3586

12. Yee SW, Campbell MJ, Simons C (2006) Inhibition of Vitamin $\mathrm{D}_{3}$ metabolism enhances VDR signalling in androgen-independent prostate cancer cells. J Steroid Biochem Mol Biol 98:228-235

13. Lechner D, Kallay E, Cross HS (2007) 1alpha,25-dihydroxyvitamin $\mathrm{D}_{3}$ downregulates CYP27B1 and induces CYP24A1 in colon cells. Mol Cell Endocrinol 263:55-64

14. Muindi JR, Nganga A, Engler KL et al (2007) CYP24 splicing variants are associated with different patterns of constitutive and calcitriol-inducible CYP24 activity in human prostate cancer cell lines. J Steroid Biochem Mol Biol 103:334-337

15. Chung I, Karpf AR, Muindi JR et al (2007) Epigenetic silencing of CYP24 in tumorderived endothelial cells contributes to selective growth inhibition by calcitriol. J Biol Chem 282:8704-8714

16. Lechner D, Manhardt T, Bajna E et al (2007) A 24-phenylsulfone analog of vitamin D inhibits 1alpha,25-dihydroxyvitamin $\mathrm{D}_{3}$ degradation in vitamin $\mathrm{D}$ metabolism-competent cells. J Pharmacol Exp Ther 320:1119-1126

17. Tan J, Dwivedi PP, Anderson P et al (2007) Antineoplastic agents target the 25hydroxyvitamin $\mathrm{D}_{3}$ 24-hydroxylase messenger RNA for degradation: implications in anticancer activity. Mol Cancer Ther 6:3131-3138 
18. Vandewalle B, Adenis A, Hornez L et al (1994) 1,25-dihydroxyvitamin $\mathrm{D}_{3}$ receptors in normal and malignant human colorectal tissues. Cancer Lett 86:67-73

19. Cross HS, Bajna E, Bises G et al (1996) Vitamin D receptor and cytokeratin expression may be progression indicators in human colon cancer. Anticancer Res 16:2333-2337

20. Evans SRT, Nolla J, Hanfelt J et al (1998) Vitamin D receptor expression as a predictive marker of biological behavior in human colorectal cancer. Clin Cancer Res 4:1591-1595

21. Eisman JA, Suva LJ, Martin TJ (1986) Significance of 1,25-dihydroxyvitamin $\mathrm{D}_{3}$ receptor in primary breast cancers. Cancer Res 46:5406-5408

22. Berger U, McClelland RA, Wilson P et al (1991) Immunocytochemical determination of estrogen receptor, progesterone receptor, and 1,25-dihydroxyvitamin $\mathrm{D}_{3}$ receptor in breast cancer and relationship to prognosis. Cancer Res 51:239-244

23. Anderson MG, Nakane M, Ruan X et al (2006) Expression of VDR and CYP24A1 mRNA in human tumors. Cancer Chemother Pharmacol 57:234-240

24. Campbell MJ, Adorini L (2006) The vitamin D receptor as a therapeutic target. Expert Opin Ther Targets 10:735-748

25. Pálmer HG, Larriba MJ, García JM et al (2004) The transcription factor SNAIL represses vitamin D receptor expression and responsiveness in human colon cancer. Nat Med 10:917-919

26. Larriba MJ, Valle N, Pálmer HG et al (2007) The inhibition of Wnt/beta-catenin signalling by 1alpha,25-dihydroxyvitamin $\mathrm{D}_{3}$ is abrogated by Snail1 in human colon cancer cells. Endocr Relat Cancer 14:141-151

27. Peña C, García JM, Silva J et al (2005) E-cadherin and vitamin D receptor regulation by SNAIL and ZEB1 in colon cancer: clinicopathological correlations. Hum Mol Genet $14: 3361-3370$

28. Larriba MJ, Muñoz A (2005) SNAIL vs vitamin D receptor expression in colon cancer: 
therapeutics implications. Br J Cancer 92:985-989

29. Peinado H, Olmeda D, Cano A (2007) Snail, Zeb and bHLH factors in tumour progression: an alliance against the epithelial phenotype?. Nat Rev Cancer 7:415-428

30. Rozenchan PB, Folgueira MAAK, Katayama MLH et al (2004) Ras activation is associated with vitamin D receptor mRNA instability in HC11 mammary cells. J Steroid Biochem Mol Biol 92:89-95

31. Agudo-Ibáñez L, Núñez F, Calvo F et al (2007) Transcriptomal profiling of site-specific Ras signals. Cell Signal 19:2264-2276

32. Larriba MJ, Valle N, Álvarez S et al (2008) Vitamin $D_{3}$ and colorectal cancer. Adv Exp Med Biol 617:271-280

33. Abedin SA, Banwell CM, Colston KW et al (2006) Epigenetic corruption of VDR signalling in malignancy. Anticancer Res 26:2557-2566

34. Khanim FL, Gommersall LM, Wood VHJ et al (2004) Altered SMRT levels disrupt vitamin $\mathrm{D}_{3}$ receptor signalling in prostate cancer cells. Oncogene 23:6712-6725

35. Banwell CM, MacCartney DP, Guy M et al (2006) Altered nuclear receptor corepressor expression attenuates vitamin D receptor signaling in breast cancer cells. Clin Cancer Res 12:2004-2013

36. Banwell CM, O'Neill LP, Uskokovic MR et al (2004) Targeting 1alpha,25dihydroxyvitamin $\mathrm{D}_{3}$ antiproliferative insensitivity in breast cancer cells by co-treatment with histone deacetylation inhibitors. J Steroid Biochem Mol Biol 89-90:245-249

37. Rashid SF, Moore JS, Walker E et al (2001) Synergistic growth inhibition of prostate cancer cells by 1alpha,25 Dihydroxyvitamin $\mathrm{D}_{3}$ and its 19-nor-hexafluoride analogs in combination with either sodium butyrate or trichostatin A. Oncogene 20:1860-1872 38. Hidalgo AA, Paredes R, García VM et al (2007) Altered VDR-mediated transcriptional activity in prostate cancer stroma. J Steroid Biochem Mol Biol 103:731-736 
39. Bikle DD, Xie Z, Ng D et al (2003) Squamous cell carcinomas fail to respond to the prodifferentiating actions of $1,25(\mathrm{OH})_{2} \mathrm{D}_{3}$ : why?. Recent Results Cancer Res 164:111-122 40. Solomon C, White JH, Kremer R (1999) Mitogen-activated protein kinase inhibits 1,25dihydroxyvitamin $\mathrm{D}_{3}$-dependent signal transduction by phosphorylating human retinoid $\mathrm{X}$ receptor alpha. J Clin Invest 103:1729-1735

\section{Figure Legends}

Figure 1. Schematic representation of $1,25(\mathrm{OH})_{2} \mathrm{D}_{3}$ metabolism and action in human cancer cells and of the mechanisms of resistance to $1,25(\mathrm{OH})_{2} \mathrm{D}_{3}$. Cancer epithelial cells receive $25(\mathrm{OH}) \mathrm{D}_{3}$ and $1,25(\mathrm{OH})_{2} \mathrm{D}_{3}$ (in the $\mathrm{nM}$ and $\mathrm{pM}$ range, respectively) from the bloodstream and synthesize $1,25(\mathrm{OH})_{2} \mathrm{D}_{3}$ from $25(\mathrm{OH}) \mathrm{D}_{3}$ by CYP27B1 action. $1,25(\mathrm{OH})_{2} \mathrm{D}_{3}$ binding to VDR induces a conformational change that leads to the replacement of corepressors (SMRT, $\mathrm{NCoR}$ ) by coactivators (SRC1, NCoA2) and finally induces the transcriptional activation of many genes involved in different cellular functions related to $1,25(\mathrm{OH})_{2} \mathrm{D}_{3}$ antitumoral action. Alteration of the expression and activity of the enzymes regulating $1,25(\mathrm{OH})_{2} \mathrm{D}_{3}$ synthesis (CYP27B1) and catabolism (CYP24A1) have been found in cancer, and they cause the reduction of intracellular $1,25(\mathrm{OH})_{2} \mathrm{D}_{3}$ levels. Similarly, VDR repression and aberrant expression of transcriptional coactivators or corepressors have been found in cancer and they lead to $1,25(\mathrm{OH})_{2} \mathrm{D}_{3}$ resistance.

Figure 2. Immunohistochemistry analysis of the expression of VDR and Snaill in xenografted tumors generated in immunodeficient mice by human SW480-ADH colon cancer cells that were infected with retroviruses coding for the hemmaglutinin (HA)-tagged mouse Snaill cDNA or an empty virus (Mock). As shown by the use of anti-VDR and anti-HA antibodies, Snail1 overexpression downregulates VDR levels. 